\title{
Herneen kasvintuhoojien kartoituksella esiin viljelyn vaikeuksia
}

\author{
Erja Huusela-Veistola, Mervi Lindroos, Heikki Jalli, Jukka Salonen
}

MTT Kasvinsuojelu, 31600 Jokioinen, etunimi.sukunimi@mtt.fi

\section{Johdanto}

Vuonna 2002 alkaneessa MTT:n tutkimushankkeessa "Kotimaista valkuaista herneestä" tutkitaan herneen viljelyvarmuutta, herneen käyttöä eläinten rehuna ja viljelyn kannattavuutta. Hankkeen kasvinsuojeluosiossa kiinnitetään huomio herneen viljelyalan mahdollisesta laajenemisesta aiheutuviin kasvinsuojeluongelmiin. Oletuksena on, että kasvintuhoojien eli kasvitautien, rikkakasvien ja tuhoeläinten aiheuttamat ongelmat lisääntyvät herneen viljelyn yleistyessä. Tutkimuksen tavoitteena on mahdollisten kasvinsuojeluongelmien ennakointi ja hallinta.

\begin{abstract}
Aineisto ja menetelmät
Kasvintuhoojia kartoitettiin käytännön herneviljelyksillä vuosina 2002 ja 2003, mutta tässä yhteydessä keskitytään vuoden 2002 tuloksiin. Tutkimuksen valmistelussa käytettiin apuna tilastotietoa (MMM/TIKE) herneen viljelyn laajuudesta vuosina 1997-2001. Tilastotiedon avulla selvitettiin herneen viljelyn yleisyys ja alueellinen jakauma. Tietojen avulla valittiin Lounais-Suomesta alueita, joilla herneen viljelyintensiteetti (viljelyala ja frekvenssi) erosivat toisistaan. Viljelyalueet luokiteltiin alkuvaiheessa neljän luokkaan viljelyn yleisyyden mukaan: $1=$ hernettä viljellään harvoin, $4=$ herneen viljely yleistä/laaja-alaista. Otantaan sisältyi ruokaherne-, rehuherne- ja seoskasvustoja. Otannassa oletettiin, ettei spatiaalista riippuvuutta esiintyisi peltolohkojen välisen etäisyyden ollessa vähintään 4 $\mathrm{km}$.

Kasvintuhoojatilanteen arvioimiseksi tarkkailulohkot havainnoitiin kolme kertaa kasvukauden aikana. Lohkoilta otettiin kullakin havainnointikerralla kasvinäytteet, joista tarkastettiin kasvitauti- ja tuhoeläinvioitukset. Lohkon rikkakasvitilanne havainnoitiin toisella tilakäynnillä. Hernekääriäismääriä arvioitiin feromonipyydyksillä kesäkuun alusta elokuun alkuun. Lisäksi tiloilta kerättiin viljelytiedot ja satonäytteet. Satonäytteistä määritettiin itävyysprosentti, taudinaiheuttajat ja tuhoeläinvioitukset.
\end{abstract}

\section{Tulokset ja tulosten tarkastelu}

\section{Viljely-ja kasvinsuojelutoimet tutkimustiloilla}

Tutkimuksessa oli vuonna 2002 mukana 93 hernelohkoa Varsinais-Suomesta, Satakunnasta, Hämeestä ja Uudeltamaalta. Tutkimuslohkoista 32 oli luomuviljeltyjä ja 61 tavanomaisia. Herneen esikasvina oli tavallisesti kevätvilja (ohra, vehnä, kaura). Yleisimmin viljellyt hernelajikkeet olivat Karita (52 lohkoa), Tiina (16 lohkoa) ja Stok (13 lohkoa). Tutkimuslohkoista 29 oli seoskasvustoja ja 64 puhdaskasvustoja. Kemiallinen tuholaistorjunta tehtiin 24 lohkolla eli alle $40 \%$ :lla tavanomaisista lohkoista. Käytetyimmät hyönteistorjunta-aineet olivat Decis ja Karate. Rikkakasvit torjuttiin kemiallisesti 55 lohkolla eli 90 \%:1la tavanomaisista lohkoista. Rikkakasvien torjunta-aineista kolme selvästi eniten käytettyä olivat Senkor, Basagran SG ja Basagran MCPA. Kasvitautitorjuntaa ei tehty millään tutkimuslohkolla. Kylvösiemenen peittauskäsittelyjä ei tiloilla tehty.

\section{Tuhoeläimet}

Vuonna 2002 herneen pahimman tuhohyönteisen, hernekääriäisen, lento alkoi poikkeuksellisen aikaisin, jo kesäkuun puolivälissä, ja sitä esiintyi runsaasti. Juovahernekärsäkkään vioitusta havaittiin taimivaiheessa jonkin verran, mutta muita tuhohyönteisiä ja niiden vioituksia esiintyi niukasti.

Hernekääriäismäärien analysoinnissa herneenviljelyn yleisyyttä kuvattiin indeksillä, joka huomioi kaikki alle $4 \mathrm{~km}: \mathrm{n}$ säteellä (eli noin $50 \mathrm{~km}^{2}$ :n alalla) olleet edellisvuoden (2001) hernelohkot ja niiden pinta-alat. $10 \%$ :lla lohkoista yleisyysindeksi oli alle 410 aaria ja $10 \%$ :lla vähintään 5130 aaria. Lisäksi analysoitiin, kuinka etäisyys edellisvuoden hernelohkoon vaikuttaa hernekääriäisen esiintymiseen. Vuoden 2002 tutkimuslohkojen mininimietäisyys lähimpään edellisvuoden hernelohkoon vaihteli välillä $0-5.5 \mathrm{~km}$.

Tuotantotavalla (luomu/tavanomainen) tai hyönteistorjunta-aineiden käytöllä ei ollut vaikutusta feromonipyydysten hernekääriäissaaliisiin. Sen sijaan pyydysten hernekääriäismäärä kasvoi merkitsevästi $(\mathrm{P}<0.001)$ herneenviljelyn yleisyysindeksin kasvaessa (Kuva 1a). Toisaalta hernekääriäismäärät vähenivät sitä mukaa, kun minimietäisyys edellisvuoden hernelohkoon kasvoi ( $\mathrm{P}=0.075)$ (Kuva 1b). 
a)

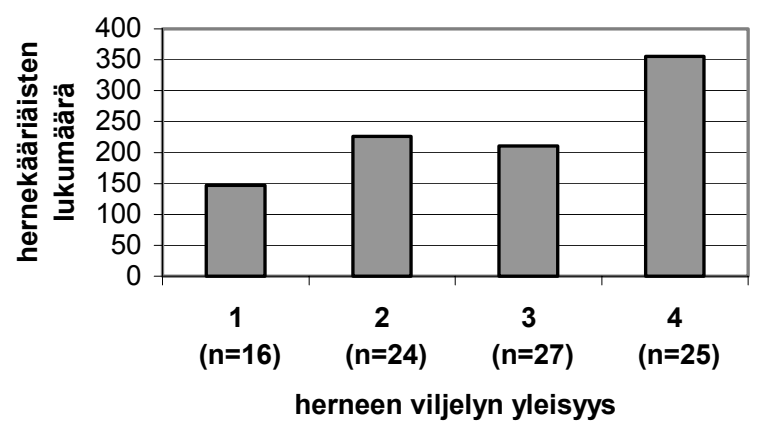

b)

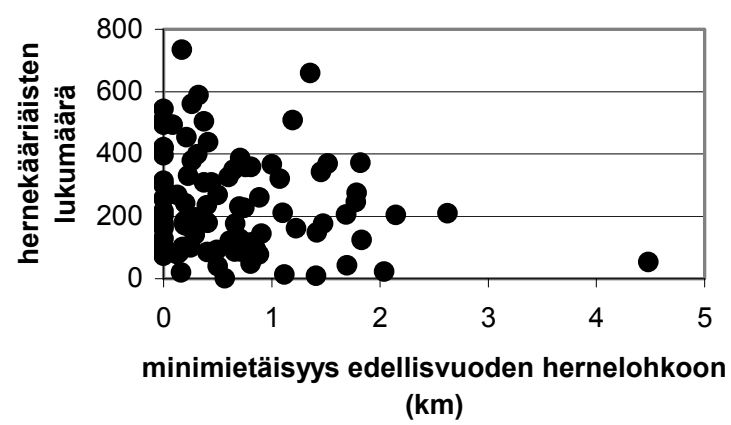

Kuva 1. a) Feromonipyydysten hernekääriäissaaliiden keskiarvot herneenviljelyn yleisyysluokissa. Viljelyn yleisyys: 1=yleisyysindeksi (= alle $4 \mathrm{~km}: n$ etäisyydellä olleiden edellisvuoden hernelohkojen pinta-alojen summa) $0-550,2=575-1455,3=1460-3030,4=3052-8955$ aaria.

b) Feromonipyydysten hernekääriäissaaliit ja etäisyys lähimpään edellisvuoden hernelohkoon (km).

Analysoitaessa hernekääriäisen vioittamien herneiden osuutta satonäytteissä ei viljelyn yleisyysindeksillä havaittu merkitsevää vaikutusta, mutta vioitusprosentti väheni selvästi, kun etäisyys edellisvuoden hernelohkosta kasvoi. Etäisyyden vaikutus ei ollut lineaarista: Mallin mukaan vioitusprosentti pienenee $6 \%$-yksikköä etäisyyden kasvaessa $0.5 \mathrm{~km}$ :stä $2.3 \mathrm{~km}$ :iin, seuraava $6 \%$ :n väheneminen tapahtuu välimatka kasvaessa 6.9 km:iin. Tuotantotapa vaikutti merkitsevästi $(\mathrm{P}=0.004)$ hernekääriäisen vioittamien herneiden osuuteen satonäytteissä. Luomulohkoilla vioittuneiden herneiden osuus oli keskimäärin $26 \%$, tavanomaisilla lohkoilla $17 \%$. Hyönteistorjunta-aineiden käyttö vähensi merkitsevästi $(\mathrm{P}=0.032)$ vioittuneiden herneiden määrää: Käsitellyillä lohkoilla keskimäärin $14 \%$ ja käsittelemättömillä lohkoilla $22 \%$ herneistä oli vioittuneita. On huomattava, että satonäytteistä mitattu vioitusprosentti on todellista pienempi, koska osa vioittuneista siemenistä joutuu puintijätteeksi.

Alustavien tulosten mukaan hernekääriäisriski näyttää olevan suurempi alueilla, joilla herneen viljely on yleistä. Lisäksi hernekääriäismääriin vaikuttaa etenkin edellisvuoden hernepeltojen sijainti: hernekääriäistä on sitä enemmän, mitä lähempänä edellisenä vuonna on viljelty hernettä. Oikein ajoitetulla kemiallisella torjunnalla voidaan vähentää vioituksen määrää. Feromonipyydykset ovat käyttökelpoisia apuvälineitä torjunta-tarvetta ja -ajankohtaa päätettäessä. Luomutuotannossa viljelykierto sekä kylvön ja korjuun aikaistaminen ovat ainoat keinot vähentää hernekääriäisriskiä.

\section{Kasvitaudit}

Tilakäynneillä kerätyistä kasveista $(25 \mathrm{kpl} /$ peltolohko $)$ tehtiin silmämääräisesti tyvi- ja juuristovioitushavainnot erikseen asteikolla $0-4(0=$ täysin terve, $4=$ kasvin tyvi tai juuri kurtistunut ja kasvi kuollut). Tyvi- ja juuristovioitusindeksiarvo (Disease Index Rating, DIR) kuvaa tautien määrää sekä ankaruutta:

$$
\mathrm{DIR}=\frac{\Sigma(\text { Kasvien kpl-määrä luokassa } \mathrm{x} \text { luokka-arvo })}{\text { Kasvien kokonaismäärä x } 4}
$$

Tyvitautien aiheuttajat tunnistettiin viimeisen havainnointikerran näytteistä. Satonäytteestä analysoitiin siemenlevintäiset taudinaiheuttajat.

Vuonna 2002 herneet kärsivät voimakkaista tyvi- ja juuristovioituksista jo kukintavaiheessa. Ensimmäisellä havainnointikerralla tyvi- ja juuristovioituksia oli melko vähän eikä kasvustoissa ollut selviä taimipolte- eikä lakastumistautivioituksia. Jo taimivaiheesta lähtien tyvi- ja juuristovioitusindeksi oli sitä suurempi mitä useammin peruslohkolla oli hernettä viljelty (Kuva 2). Tutkimuksessa mukana olleiden tilojen peruslohkojen viljelykierrot olivat hyvin erilaisia. 43 tavanomaisesti viljellyllä tilalla viljelykierto oli riittävä, vähintään 5 vuotta, mutta 18 tilalla viljelykierto oli riittämätön, hernettä viljeltiin peruslohkolla vähintään joka kolmas vuosi. Luomutiloilla riittävän pitkä viljelykierto oli 18 tilalla ja liian hernevaltainen viljelykierto oli 14 tilalla. Herneen viljelyssä suositellaan 4-5 vuoden viljelykiertoa, koska herneen tärkeimmät taudinaiheuttajat voivat säilyä maassa pitkään kestoasteidensa avulla. Lisäksi ne voivat siirtyä maa-aineksen myötä peruslohkon sisällä kasvulohkosta toiseen muokkaustoimenpiteiden mukana. 
a)

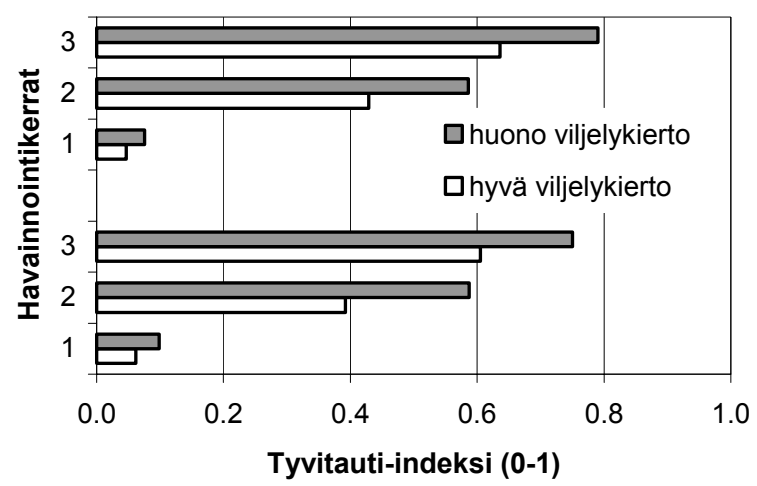

b)

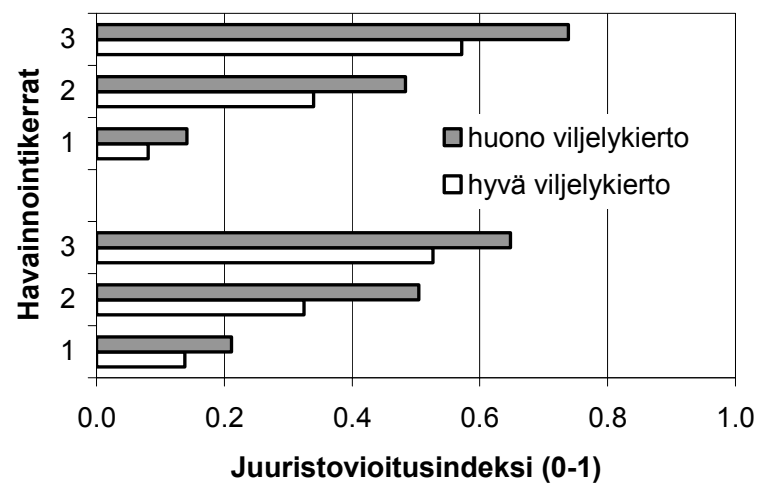

Kuva 2 a). Tyvitauti-indeksi viljelykierroltaan toisistaan poikkeavilla tavanomaisesti viljellyillä ja luomutiloilla. b) Juuristovioitusindeksi viljelykierroltaan toisistaan poikkeavilla tavanomaisesti viljellyillä ja luomutiloilla. Havainnointikerrat: $1=$ taimivaihe, $2=$ kukintavaihe, $3=$ tuleentumisvaihe. Huono viljelykierto $\leq 3$ vuotta, hyvä viljelykierto $\geq 4$ vuotta

Herneen tyviä vioittivat pahimmin Fusarium- ja Ascochyta-sienet. $75 \%$ :1la tiloista herneen tyviä vioittivat Fusarium-sienet ja 77 \%:1la tiloista taudinaiheuttajana olivat Ascochyta-sienet. Pääsääntöisesti sienet esiintyivät sekainfektiona. Jo 1970-luvulla tehdyssä herneen taudinaiheuttajia kartoittaneessa tutkimuksessa, todettiin yleisimpien ja tärkeimpien tyvitaudinaiheuttajien olevan Ascochyta- ja Fusarium-sieniä. Tutkimuksen mukaan Ascochyta-sienet yhdessä sekundääristen homesienien kanssa alentavat siemenen itävyyttä (Ruokola \& Kössi 1977). Seurantatiloilta kerätyissä satonäytteissä keskimäärin $8 \%$ siemenistä oli Ascochyta- ja $9 \%$ Fusarium-sienten tartuttamia. Satonäytteiden keskimääräinen itävyys oli 83 \% vaihdellen tilakohtaisesti 19-100 \% välillä. Taudinaiheuttajien määrä ei yksistään selittänyt itävyyden vaihtelua.

Herneen merkittävimmät tyvitautien aiheuttajat, Fusarium- ja Ascochyta-sienet, ovat sekä siemen- että maalevintäisiä. Leviämismekanismiensa puolesta taudinaiheuttajia voitaisiin pitää kurissa kylvösiemen peittauksella, jos markkinoilla olisi käyttökelpoisia torjunta-aineita. Lisäksi vähintään 45 vuoden viljelykiertoa tulisi noudattaa. Fusarium-sieniin on vaikea vaikuttaa viljelykierrolla, koska ne ovat moni-isäntäisiä. Sitä vastoin Ascochyta-sienien vioituksia voidaan pitää kurissa noudattamalla vähintään 4 vuoden viljelykiertoa.

\section{Rikkakasvit}

Heinäkuussa tutkimuslohkoilla havainnoitiin rikkakasvilajien peittävyys luokittain viideltä näytealalta, sekä lisäksi pelto-ohdakkeen, peltovalvatin ja juolavehnän laikuttainen esiintyminen lohkolla. Tällöin oli tavanomaisesti viljellyillä pelloilla tehty mahdollinen herbisidikäsittely.

Herneen kilpailukyky rikkakasveja vastaan on heikko. Kaiken kaikkiaan luomupelloilta löytyi 62 eri rikkakasvilajia ja tavanomaisesti viljellyiltä lohkoilta 53 lajia. Luomupelloilla siemenrikkakasveja jauhosavikkaa, pillikkeitä, peltoukonnaurista ja pihatähtimöä oli kutakin yli 90:1lä \%:1la lohkoista (Kuva 3). Hyvönen et al. (2003) totesivat savikan dominoivan myös luomuviljapelloilla. Tavanomaisilla lohkoilla jauhosavikka, orvokit ja pihatähtimö olivat yleisimmät lajit.

Kestorikkakasveista peltovalvatti oli luomupelloilla yleisin. Peltovalvattia oli lähes $85 \%$ :lla luomuhernepelloista, kun tavanomaisesti viljellyillä pelloilla sitä oli alle puolella. Juolavehnä oli tavanomaisesti viljeltyjen hernepeltojen yleisin kestorikkakasvi. Pelto-ohdake oli kolmanneksi yleisin kestorikkakasvi ja sitä oli useimmin luomupellolla kuin tavanomaisesti viljellyillä pelloilla. Kestorikkakasvien esiintyminen vastaa hyvin 1990-luvun lopun luomu- ja tavanomaisesti viljeltyjen kevätviljapeltojen tilannetta (Salonen \& Hyvönen 2002).

Tavanomaisessa herneenviljelyssä rikkakasvit torjuttiin kemiallisesti $90 \%$ :lla lohkoista. Torjunta tehtiin bentatsonilla 26 lohkolla, joista seoksena MCPA:n kanssa 18 lohkolla. Aklonifeenin ja bentatsonin seoksella rikkakasvit torjuttiin kolmella lohkolla, ja yhdellä pelkällä aklonifeenilla. Metributsiinia käytettiin 21 lohkolla. Hernekasvustosta on mahdollista torjua rikkakasvit tehokkaasti, mutta torjunta-ainekustannus on tällöin moninkertainen verrattuna viljapellon rikkakasvitorjunnan kustannukseen. Hernekasvustoissa voi käyttää tehokkaasti valikoivia juolavehnäntorjunta-aineita, 
mutta niihin turvauduttiin vain viidellä lohkolla, vaikka juolavehnää esiintyi yli puolella tavanomaisesti viljellyistä lohkoista.

a)

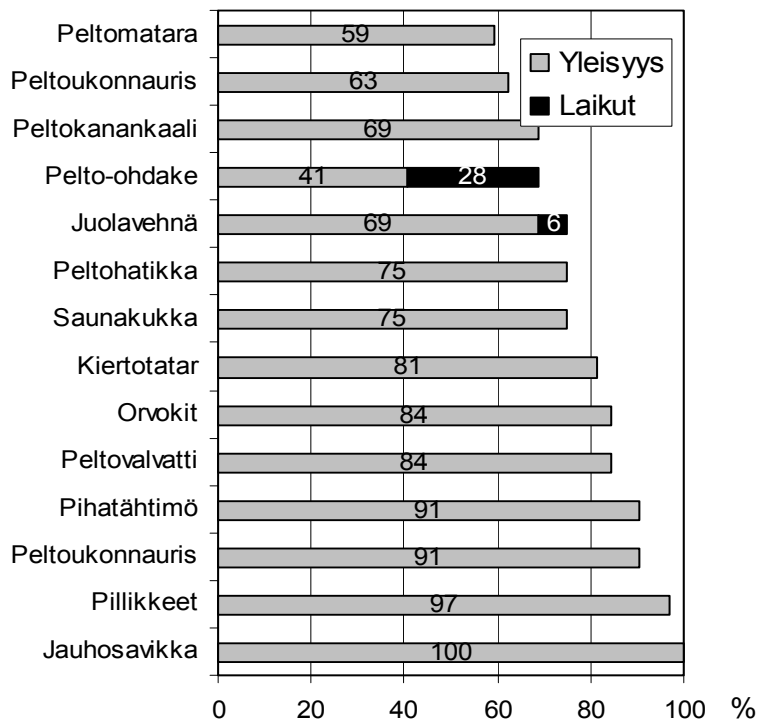

b)

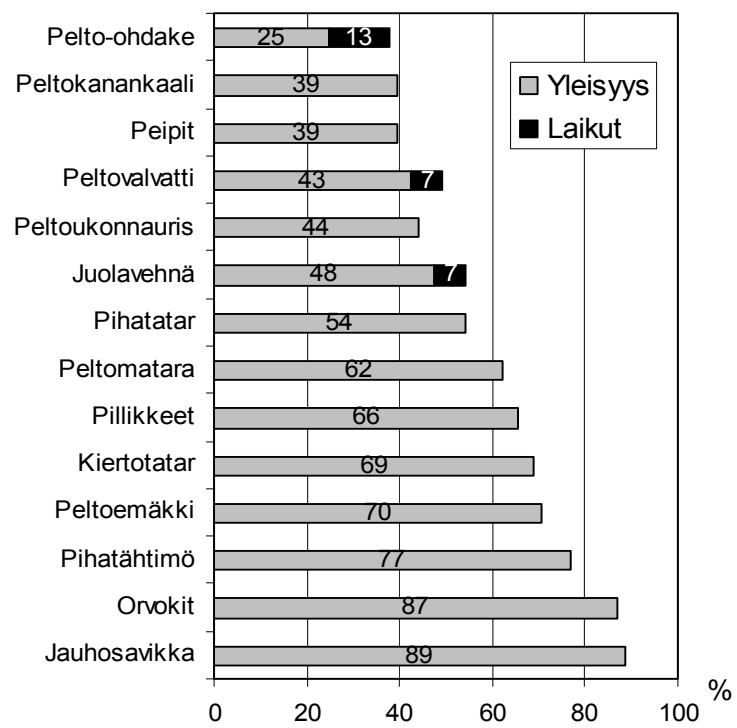

Kuva 3. Rikkakasvilajien esiintymien prosenttiosuudella a) luomupeltoja ja b) tavanomaisesti viljeltyjä hernepeltoja. Harmaa pylvään osuus kuvaa esiintymistä näytealalla ja musta lisä havaittuja esiintymislaikkuja lohkolla.

\section{Johtopäätökset}

Kasvintuhoojaongelmat liittyvät ennen kaikkea viljelymittakaavaan. Viljelyalan kasvu ja herneen viljely entistä useammin samalla lohkolla lisäävät herneen tuhoeläinten ja kasvitautien esiintymisrunsautta ja tuhojen määrää. Rehuherneen tuotannon laajeneminen voi lisätä tuore- ja ruokaherneen tuotannon kasvintuhoojaongelmia, mikä on huomioitava alueellisesti tuotannon lisäystä suunniteltaessa. Myös hallituilla viljelykierroilla voidaan vähentää herneenviljelyn kasvintuhoojaongelmia.

\section{Kirjallisuus}

Hyvönen, T., Ketoja, E., Salonen, J., Jalli, H., \& Tiainen, J. 2003. Weed species diversity and community composition in organic and conventional cropping of spring cereals. Agriculture, Ecosystems \& Environment 97: 131-149.

Ruokola, A-L. \& Kössi, L. 1977. Fungus diseases of pea seeds and stands in Finland. Acta Agriculturea Scandinavica 27: 89-104

Salonen, J. \& Hyvönen, T. 2002. Perennial weeds in conventional and organic cropping of spring cereals in Finland. Zeitschrift für Pflanzenkrankheiten und Pflanzenschutz 109: 519-525. 